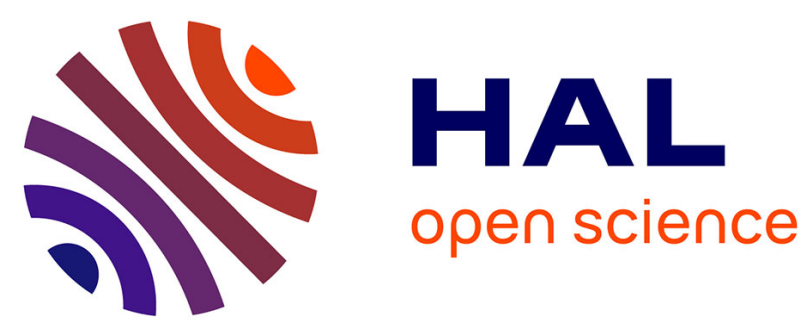

\title{
Structure and causes of the pulsation mode in the Antarctic circumpolar current South of Australia
}

C. Dufour, J. Le Sommer, T. Penduff, B. Barnier, M. England

\section{To cite this version:}

C. Dufour, J. Le Sommer, T. Penduff, B. Barnier, M. England. Structure and causes of the pulsation mode in the Antarctic circumpolar current South of Australia. Journal of Physical Oceanography, 2011, 41 (2), pp.253 - 268. 10.1175/2010JPO4193.1 . hal-01893898

\section{HAL Id: hal-01893898 \\ https://hal.science/hal-01893898}

Submitted on 24 Aug 2021

HAL is a multi-disciplinary open access archive for the deposit and dissemination of scientific research documents, whether they are published or not. The documents may come from teaching and research institutions in France or abroad, or from public or private research centers.
L'archive ouverte pluridisciplinaire HAL, est destinée au dépôt et à la diffusion de documents scientifiques de niveau recherche, publiés ou non, émanant des établissements d'enseignement et de recherche français ou étrangers, des laboratoires publics ou privés. 


\title{
Structure and Causes of the Pulsation Mode in the Antarctic Circumpolar Current South of Australia
}

\author{
C. O. Dufour And J. Le SOMMER \\ Laboratoire des Ecoulements Géophysiques et Industriels, CNRS/UJF/INPG, Grenoble, France \\ T. PENDUFF \\ Laboratoire des Ecoulements Géophysiques et Industriels, CNRS/UJF/INPG, Grenoble, France, and Department \\ of Oceanography, The Florida State University, Tallahassee, Florida \\ B. BARNIER \\ Laboratoire des Ecoulements Géophysiques et Industriels, CNRS/UJF/INPG, Grenoble, France \\ M. H. ENGLAND \\ Climate Change Research Center, University of New South Wales, Sydney, New South Wales, Australia
}

(Manuscript received 1 December 2008, in final form 27 July 2010)

\begin{abstract}
The subsurface variability of potential temperature and salinity south of Australia along $130^{\circ} \mathrm{E}$ is studied over a 25-yr period (1980-2004). The study is done with fields provided by a global eddy-permitting model of the DRAKKAR project forced by atmospheric reanalysis. The analysis performed by C. Sun and D. R. Watts with in situ hydrographic data is repeated. Sun and Watts have investigated the EOF modes in streamfunction space along the World Ocean Circulation Experiment (WOCE) SR3 section. In particular, they found that an EOF mode, which they called the "pulsation mode," strongly dominates subsurface thermohaline variations. Here, it is found that, in the model, an EOF mode with spatial structure similar to the Sun and Watts pulsation mode dominates subsurface thermohaline variations in streamfunction space. The mode displays a maximum of variability at the Subantarctic Front (SAF) between Subantarctic Mode Water (SAMW) and Antarctic Intermediate Water (AAIW). The associated time series exhibits an intermittent interseasonal frequency (3-6 months), especially during three periods (1983-84, 1990, and 1994-96). Some energy is also found with a 4 -yr period.

Further analyses reveal that the pulsation mode can also be observed in physical space. The pulsation mode is found to be related to movements of the SAF constrained by the bathymetry of the Southeast Indian Ridge. The pulsation mode displays many similarities with cold-core eddy events rather than being related to variations of the westerly wind stress, as previously proposed. The impact of those events on SAMW properties remains unclear.
\end{abstract}

\section{Introduction}

Perhaps the most important climate process operating in the Southern Ocean is the overturning circulation associated with the flow of dense deep waters and the compensating return flow of light upper waters within

Corresponding author address: Carolina O. Dufour, Laboratoire des Ecoulements Géophysiques et Industriels, CNRS/UJF/INPG, BP53, 38041 Grenoble CEDEX 9, France.

E-mail: carolina.dufour@hmg.inpg.fr the Antarctic Circumpolar Current (ACC; Sloyan and Rintoul 2001; Speer et al. 2000). Far-originated water masses thus outcrop south of the ACC and acquire new properties imprinted by the atmosphere. New water masses are then created and exported northward, where they take part in the global thermohaline circulation (Sloyan and Rintoul 2001). These water masses, including Subantarctic Mode Water (SAMW) and Antarctic Intermediate Water (AAIW), are important for uptake and storage of heat, salt, and carbon (Metzl et al. 1999; Banks et al. 2002), which they preserve after subduction. Therefore, the vertical 
structure of the ACC and the upper-ocean return limb of the overturning flow are major factors that constrain the meridional transport of heat, salt, and other properties at a global scale.

The circulation of the ACC is characterized by strong fronts, which separate regions of differing water-mass characteristics (Orsi et al. 1995). Fronts are usually defined by criteria based on the interior hydrographic structure (Orsi et al. 1995), but many studies recently introduced new frontal definitions based on sea surface temperature (SST) or sea surface height (SSH) criteria provided by satellite data (e.g., Gille 1994; Sokolov and Rintoul 2002, 2007a; Sallée et al. 2008). The largest variability south of Tasmania is found between $48^{\circ}$ and $53^{\circ} \mathrm{S}$, which corresponds to the mean latitudes of the Subantarctic Front (SAF) and the Polar Front (PF; Sokolov and Rintoul 2002). These fronts exhibit the strongest horizontal property gradients in this region and carry most of the transport. Usually, the SAF is defined as the location of the maximum temperature gradient between $3^{\circ}$ and $8^{\circ} \mathrm{C}$ at 300-m depth (Belkin and Gordon 1996). It is the strongest front and the main jet of the ACC south of Australia, and the enhanced horizontal gradients of the SAF extend from the sea surface to the sea floor (Sokolov and Rintoul 2002). The PF is usually defined as the northern limit of the winter water tongue, with temperatures cooler than $2^{\circ} \mathrm{C}$ at $200-\mathrm{m}$ depth (Belkin and Gordon 1996). It marks the northern limit of the Antarctic zone (Gordon et al. 1977). The ACC fronts exhibit complex spatial variability (Sokolov and Rintoul 2002, 2007a), and it has been observed that they can be occasionally shifted by a few degrees of latitude from their mean pathway (Gille 1994). Position and intensity of the fronts are mainly steered by bathymetry (Gille 1994; Sokolov and Rintoul 2002, 2007a; Sallée et al. 2008). Because the ACC is strongly wind forced (e.g., Cai and Baines 1996; Gille et al. 2001), the time variability of the fronts is likely to be driven by atmospheric forcing at least locally.

From a climate perspective, there is strong interest in long-term variability and change in water-mass properties, and therefore it is useful to filter out the variability associated with ACC frontal motion. Sun and Watts (2002a) approached this by projecting the temperature and salinity fields from six repeat hydrographic surveys along the World Ocean Circulation Experiment (WOCE) SR3 section onto a baroclinic streamfunction coordinate, defined as the dynamic height at $1000 \mathrm{dbar}$ relative to $3000 \mathrm{dbar}$. The time mean fields obtained were similar to their gravest empirical mode (GEM) field that was shown to explain more than $97 \%$ of the subsurface thermohaline variance (Sun and Watts 2001). They thus concluded that the coordinate transformation effectively filters out the temporal variability associated with fronts and mesoscale eddies.

Sun and Watts (2002a) focused on the thermohaline variations of the residual field obtained after removal of the time mean field, using an empirical orthogonal function (EOF) analysis to identify the most energetic modes. Their dominant mode is associated with thermohaline variations in the subsurface layers (300-3000 dbar) south of Australia. In the positive phase of this mode, both temperature and salinity of the SAMW increase. In the same phase and in this projection in streamfunction space, a meridional cross section shows a reduced area of AAIW and a higher salinity at the core of Circumpolar Deep Water (CDW). The position of maximum variability was found to correspond to the largest horizontal property gradients at 500-700 dbar at SAMW/ AAIW interface. Based on their limited temporal sampling, Sun and Watts suggested that the mode shows a semiannual frequency, which they also found to be a dominant signal in wind stress variations and in the ACC barotropic transport. They called this dominant mode of variability the "pulsation mode." They finally hypothesized that the pulsation mode was an oceanic barotropic response to the large-scale, low-frequency variation of the westerly wind strength. They also suggested that the deep layer thermohaline variability associated with the pulsation mode was related to anomalous zonal advection of salt due to the variation of ACC barotropic transport.

Because Sun and Watts's (2002a) characterization of the pulsation mode is based on relatively few and intermittent in situ data, we consider the dominant mode of variability in this region using a high-resolution ocean model. With the model, we can then more completely describe the variability and investigate the physical processes that control this mode. We find that indeed the dominant mode of subsurface variability has the same spatial structure as the Sun and Watts pulsation mode but the frequency content differs and is broader, including intermittent seasonal and 4-yr time scales. We do not find that this mode is clearly related to the wind but rather is associated with variable splitting and meandering of the Subantarctic Front in the vicinity of the Southeast Indian Ridge. In what follows, we retain the term "pulsation mode," even though this paper will show that the variability being discussed is not related to the pulsation of water-mass volume as suggested previously.

The rest of this paper is set out as follows: In section 2, the method Sun and Watts (2002a) used to look for the dominant mode of variability (the pulsation mode) is described and details of DRAKKAR eddy-admitting model are provided. The results of the Sun and Watts method applied to subsurface waters in the model are described in 
section 3. Then, some limitations on the baroclinic streamfunction projection method are demonstrated and the existence of the pulsation mode in physical space is assessed in section 4. Finally, we discuss some hypotheses regarding the origin of the pulsation mode in section 5 . A summary and conclusions are given in section 6 .

\section{Numerical model and analysis methods}

\section{a. Ocean model}

Throughout this study, we use model output from an eddy-admitting simulation performed during the DRAKKAR project and based on the Nucleus for European Modeling of the Ocean (NEMO) system (Madec 2008). The system is built on a hierarchy of models including an ocean general circulation model [Océan Parallélisé (OPA)] and a sea ice model [Louvain-laNeuve sea ice model (LIM)]. The simulations are forced at the surface by a daily reconstruction of atmospheric winds, water fluxes [40-yr European Centre for MediumRange Weather Forecasts (ECMWF) Re-Analysis (ERA40)], and radiative fluxes calculated from satellite observations (Brodeau et al. 2009). The simulation used in this study comes from the ORCA025-G70 global run (Treguier et al. 2007) performed at an eddy-admitting resolution of $1 / 4^{\circ}$ (Barnier et al. 2006; DRAKKAR Group 2007) and covering the last $47 \mathrm{yr}$ of the simulation (19582004). The simulation we are using, ORCA025-G70, has been proven realistic on various aspects at global scale (e.g., Lombard et al. 2009) and at regional scales (e.g., Biastoch et al. 2008a,b,c; Lübbecke et al. 2008; Lique et al. 2009; Le Sommer et al. 2009), particularly in the Southern Ocean (Renner et al. 2009; Treguier et al. 2010; Sokolov and Rintoul 2007b; Treguier et al. 2007). This simulation has been assessed more thoroughly after a space-time collocation onto altimeter observations (Penduff et al. 2010) and on various types of hydrographic data (KochLarrouy et al. 2010); these studies revealed the realism of the solution, particularly in the Southern Ocean. Because it is doubtful that atmospheric reanalyses correctly reproduce the interseasonal variability in the presatellite era (Bromwich and Fogt 2004; Hertzog et al. 2006; Dell'Aquila et al. 2007), we choose to focus on the 1980-2004 period. The model output used hereafter thus consists of temperature and salinity fields along a section at $130^{\circ} \mathrm{E}$ south of Australia averaged over 5-day periods from 1980 to 2004.

\section{b. Regional consistency of the model simulation}

The mean positions of the SAF and the PF in our simulation are determined using the hydrographic criteria described in the previous section, barotropic transport and temperature gradients. Figure 1a shows the mean temperature state along the $130^{\circ} \mathrm{E}$ section. The SAF is located at around $49^{\circ} \mathrm{S}$, where the horizontal gradients extend from the sea surface to the sea floor and where a maximum of transport exists (not shown). An analysis of the upper layers in Fig. 1a was used to locate the northernmost extent of the subsurface temperature minimum cooler than $2^{\circ} \mathrm{C}$ where the $2^{\circ} \mathrm{C}$ isotherm dips abruptly below $200 \mathrm{~m}$. This corresponds to the position of the southern branch of the $\mathrm{PF}$, which is located at roughly $58^{\circ} \mathrm{S}$ in the model simulation.

The characteristics of water masses north and south of the SAF are summarized in Fig. 2 using potential temperature-salinity diagrams for waters between a depth of 200 and $2500 \mathrm{~m}$ and potential density from $\sigma_{0}=$ $26.5 \mathrm{~kg} \mathrm{~m}^{-3}$ to $\sigma_{0}=28.0 \mathrm{~kg} \mathrm{~m}^{-3}$. As expected, warm and salty waters are found north of the SAF (see also Figs. $1 \mathrm{a}, \mathrm{b})$. The weakly stratified SAMW is centered at $\sigma_{0}=$ $26.8 \mathrm{~kg} \mathrm{~m}^{-3}$ between 0 and $700 \mathrm{dbar}$, with potential temperature from $8^{\circ}$ to $10^{\circ} \mathrm{C}$. The low salinity layer (34.2$34.4 \mathrm{psu}$ ), which appears in Figs. 1a,b at intermediate depth, is typical of AAIW and can be traced back to the surface south of the SAF. In the model run, the AAIW is centered at $\sigma_{0}=27.3 \mathrm{~kg} \mathrm{~m}^{-3}$ at $800-1000$ dbar and $2^{\circ}-4^{\circ} \mathrm{C}$. The model mean AAIW is therefore slightly denser and colder than observed (Georgi 1979).

\section{c. EOF analysis in streamfunction space}

We next map the water properties in baroclinic streamfunction space, following Sun and Watts (2002a), who used the dynamic height at 1000 dbar relative to 3000 dbar,

$$
\phi_{1000-3000}(p)=\frac{1}{g} \int_{1000 \mathrm{dbar}}^{3000 \mathrm{dbar}} \delta d p^{\prime},
$$

where $\delta$ is the specific volume anomaly,

$$
\delta(p, \theta, S)=\alpha(p, \theta, S)-\alpha(p, 0,35) ;
$$

$g$ is gravity $\left(9.81 \mathrm{~m} \mathrm{~s}^{-2}\right)$; and $p, \theta$, and $S$ refer to pressure, potential temperature, and salinity, respectively.

The mean dynamic height $\phi_{1000-3000}$ in the region south of Australia from the model in shown in Fig. 3. The location of the Southeast Indian Ridge crest is also shown as a thick black line in Fig. 3. Dynamic height contours corresponding to the SAF and the PF are materialized as thick lines. The SAF lies on the northern flank of the Southeast Indian Ridge as typically found in observations (Morrow et al. 2004). The dynamic height values corresponding to the SAF $\left(\phi_{1000-3000}=0.95 \mathrm{~m}\right)$ and the PF $\left(\phi_{1000-3000}=0.95 \mathrm{~m}\right)$ have been chosen on the basis of hydrographic and dynamic criteria. Those 

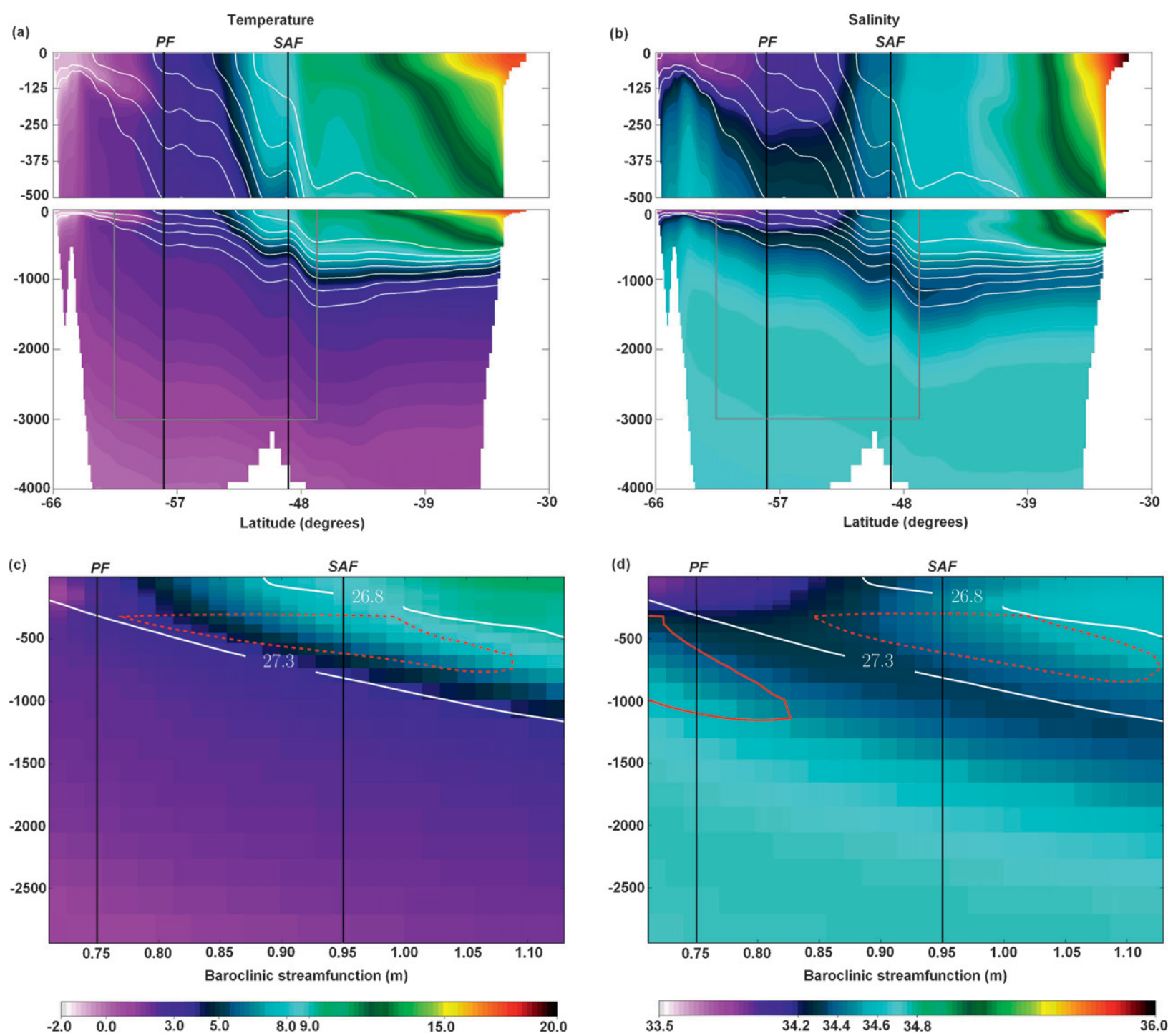

FIG. 1. Mean (a),(c) potential temperature and (b),(d) salinity cross section along $130^{\circ}$ E, in the DRAKKAR model. (a),(b) Fields in physical plane (latitude, $p$ ), a zoom on the upper $500 \mathrm{~m}$ is done; white contours indicate isopycnals ranging from $\sigma_{0}=26.8 \mathrm{~kg} \mathrm{~m}^{-3}$ to $\sigma_{0}=$ $27.4 \mathrm{~kg} \mathrm{~m}^{-3}$ with a $0.1 \mathrm{~kg} \mathrm{~m}^{-3}$ contour interval. (c),(d) Fields in streamfunction plane $\left(\phi_{1000-3000}, p\right)$. The latitude band used ranges from $45^{\circ}$ to $60^{\circ} \mathrm{S}$. Color bars indicate potential temperature $\left({ }^{\circ} \mathrm{C}\right)$ and salinity (psu). Continuous and dashed red contours indicate the location of the main anomalies in the EOF analysis (see below). White solid contours indicate the mean position of isopycnal $\sigma_{0}=26.8 \mathrm{~kg} \mathrm{~m}{ }^{-3}$ and isopycnal $\sigma_{0}=27.3 \mathrm{~kg} \mathrm{~m}^{-3}$, respectively.

definitions differ slightly from those given by Sun and Watts (2002b), particularly for the PF. One possible source of discrepancy could be model bias because the model AAIW is slightly denser than observed or systematic bias in estimation of frontal location because of the irregularity of the Sun and Watts (2002b) time sampling. In addition, the Sun and Watts (2002b) study used a circumpolar definition of the ACC fronts, so their criteria might not be optimal for this region.

We next follow Sun and Watts's (2002b) approach for projecting potential temperature and salinity in streamfunction (dynamic height) coordinates. Sun and Watts (2002b) presumed that the location of a dynamic front such as the SAF is uniquely determined by the baroclinic streamfunction parameter (dynamic height). This is due to the vertical structure of the ACC being mostly equivalent barotropic (Killworth 1992). One can therefore define the mean field in streamfunction space, the so-called mean GEM field (Sun and Watts 2001), by projection onto a depth-independent streamfunction parameter. Mean potential temperature and salinity fields projected onto the streamfunction coordinate 

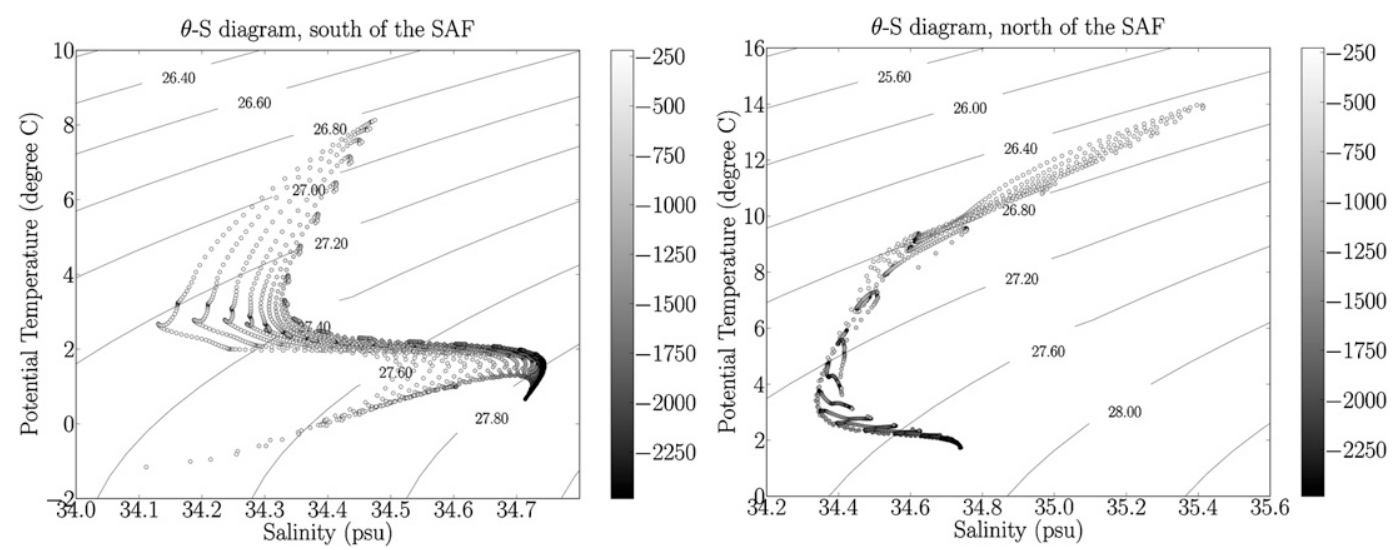

FIG. 2. Subsampled temperature-salinity diagram (left) south and (right) north of the SAF along $130^{\circ} \mathrm{E}$ for a latitude ranging from $30^{\circ}$ to $66^{\circ} \mathrm{S}$ in the DRAKKAR model, showing the thermohaline properties averaged over $25 \mathrm{yr}$ (1980-2004). A $\theta-S$ point is drawn for each grid point of the model located between a depth of 200 and $2500 \mathrm{~m}$ along $130^{\circ} \mathrm{E}$ and whose surface-referenced potential density ranges from $\sigma_{0}=26.5 \mathrm{~kg} \mathrm{~m}^{-3}$ to $\sigma_{0}=28.0 \mathrm{~kg} \mathrm{~m}^{-3}$. The SAF is located at $49^{\circ} \mathrm{S}$. Gray shades on the vertical bar represent the depth (dbar), and the background contours indicate isopycnals $\left(\mathrm{kg} \mathrm{m}^{-3}\right)$.

$\phi_{1000-3000}$ using a cubic spline interpolation, following Sun and Watts (2002a), are plotted in Figs. 1c,d. Comparison with the fields as a function of latitude (Figs. $1 \mathrm{a}, \mathrm{b})$ shows that the transformation clearly retains the structure found in physical space but obviously results in distortion of the physical space by spreading tight fronts such as the SAF over a large range of streamfunction.

Following Sun and Watts (2002a), we use a timedependent projection to filter out the variability associated with fronts (such as meridional motions of the ACC fronts and mesoscale eddies) using the streamfunction projection method on the 5-day mean running potential temperature and salinity fields. A four-dimensional (4D) matrix $M$ (time, depth, latitude, longitude $=130^{\circ} \mathrm{E}$ ) gathering data along the section at $130^{\circ} \mathrm{E}$ over $25 \mathrm{yr}$ with a 5-day frequency is built. The mean field from $M$ is then removed and the residual matrix is normalized by the standard deviation. An EOF analysis is then applied to the subsurface waters (at depths of 300-3000 dbar) following Sun and Watts (2002a). Sun and Watts presumed that changes identified by the EOFs should not a priori be due to frontal motions, because the main effect of frontal motions would be simply to shift the streamlines and the water masses laterally, without altering watermass properties. However, we will see that the SAF structure in this region is more complex than assumed by Sun and Watts, often splitting or meandering into several fronts (e.g., Sokolov and Rintoul 2007a). Cold-core rings also appear in this region (Morrow et al. 2004). These lead to a nonuniqueness of the mapping from physical to streamfunction space; therefore, in fact, water-mass variability in this space can be contaminated by frontal splitting.

\section{Characterizing the dominant mode of variability}

\section{a. Dominant mode in the subsurface waters}

The first EOFs for subsurface potential temperature and salinity in streamfunction space are plotted in Figs. 4a,c. The first EOF mode clearly dominates both potential temperature and salinity variance below $300 \mathrm{dbar}$, capturing $58.7 \%$ and $63.7 \%$ of the variance, respectively. Maximum amplitude of variations reaches $0.8^{\circ} \mathrm{C}$ for

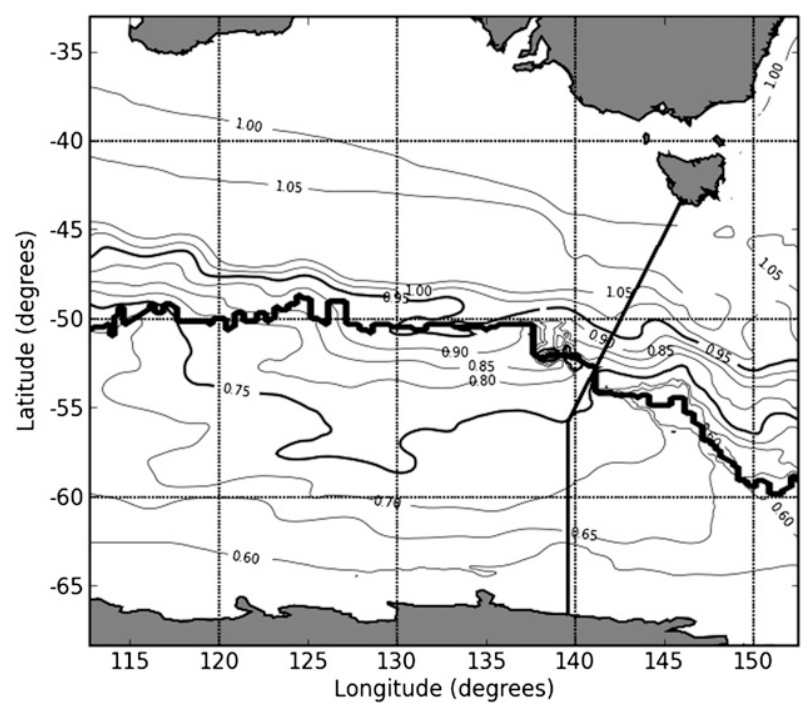

FIG. 3. Mean baroclinic streamfunction parameter $\left(\phi_{1000-3000}\right)$ isolines (meters) in the vicinity of the $130^{\circ} \mathrm{E}$ section, in the DRAKKAR model. Isolines $\phi_{1000-3000}=0.95$ and $0.75 \mathrm{~m}$ are drawn thicker than the others. The thick dark sinuous contour indicates the Southeast Indian Ridge crest. The black straight line indicates the location of the WOCE SR3 line. 
(a)

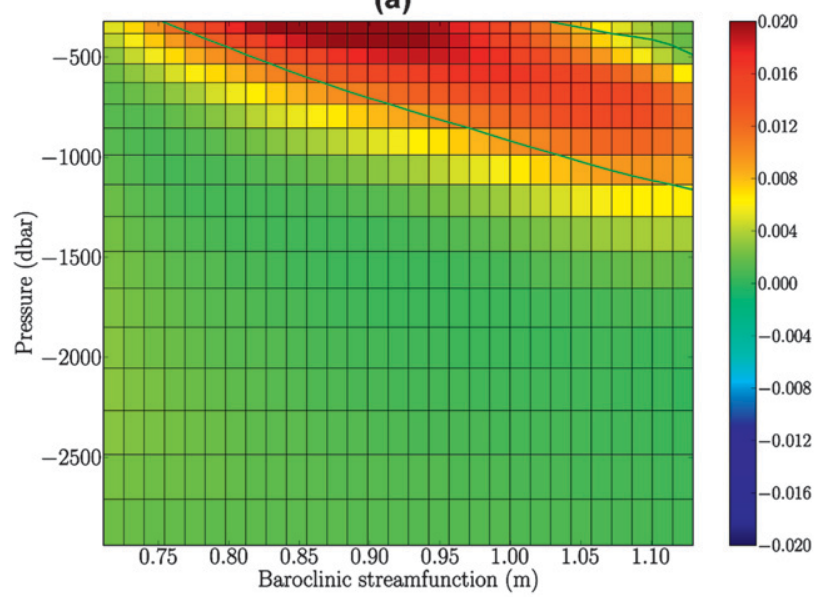

(c)

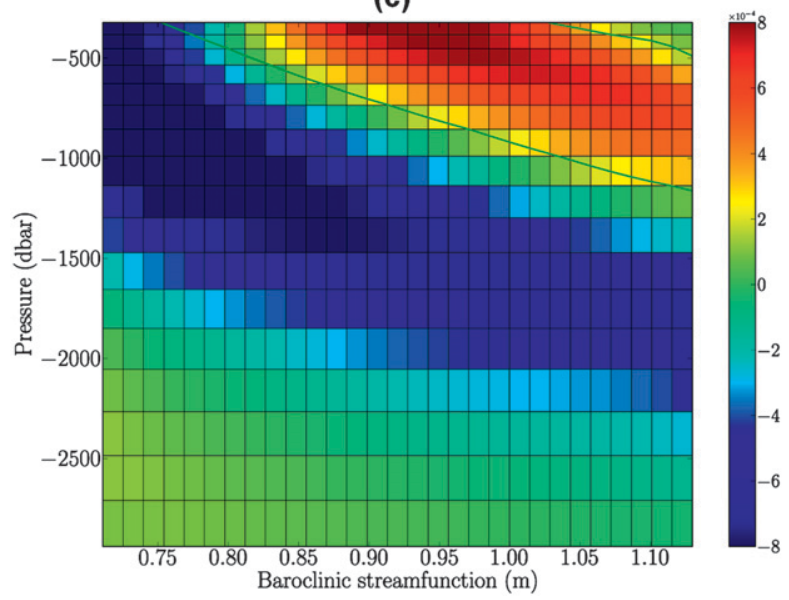

(b)

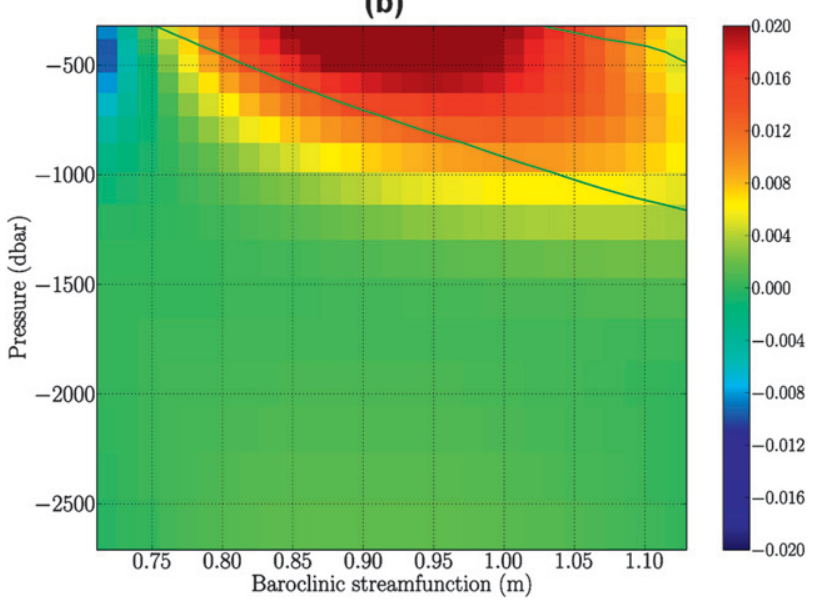

(d)

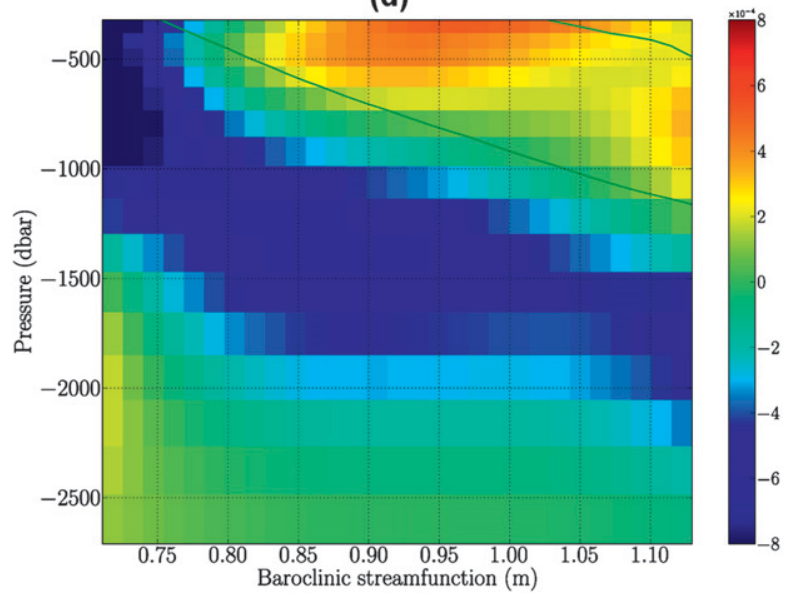

FIG. 4. First DRAKKAR model EOF for (a),(b) potential temperature and (c),(d) salinity within the 300-3000-dbar layer calculated (a),(c) in streamfunction space and (b),(d) in physical space then projected into streamfunction space. The latitude band used ranges from $45^{\circ}$ to $60^{\circ} \mathrm{S}$. Green lines indicate isopycnals $\sigma_{0}=26.8 \mathrm{~kg} \mathrm{~m}^{-3}$ (upper line) and $27.3 \mathrm{~kg} \mathrm{~m}^{-3}$ (lower line).

potential temperature and 0.05 psu for salinity. The spatial structure of the first EOF mode shows a positive anomaly present on both potential temperature and salinity patterns and located in the SAF zone at the 300-dbar level. The average positions in streamfunction space of isopycnals $\sigma_{0}=26.8 \mathrm{~kg} \mathrm{~m}^{-3}$ and $\sigma_{0}=$ $27.3 \mathrm{~kg} \mathrm{~m}^{-3}$ corresponding to SAMW and AAIW, respectively, are plotted on the potential temperature and salinity sections in Figs. 4a,c. They reveal that the observed anomaly is concentrated at the SAMW and AAIW interface. These features agree well with the equivalent modes described by Sun and Watts.

A covariate EOF analysis is next applied to $\alpha \times \theta$ and $\beta \times S$, where $\alpha$ is the thermal expansion coefficient and $\beta$ is the saline contraction coefficient. A mode with spatial structure and temporal variability very similar to those obtained with univariate EOF analyses is found (not shown). EOF analyses of spiciness (Flament 2002) and surface-referenced potential density $\sigma_{0}$ have also been carried out and both exhibit a dominant mode consistent with the potential temperature and salinity patterns seen in Figs. 4a,c (not shown). The spatial patterns of our first EOF match that of the dominant mode identified by Sun and Watts. Thus, in terms of spatial structure, the DRAKKAR model exhibits the pulsation mode, if it is defined as in Sun and Watts, as the first EOF of subsurface thermohaline variability.

\section{b. Time-frequency analysis}

The time series of amplitude of first EOF mode of potential temperature and salinity are similar (Fig. 5, top). These signals exhibit too much high-frequency variability (i.e., frequencies below a month) to clearly observe interseasonal or semiannual frequencies in the raw principal component time series. To observe the dominant frequency and its distribution over the $25-\mathrm{yr}$ 

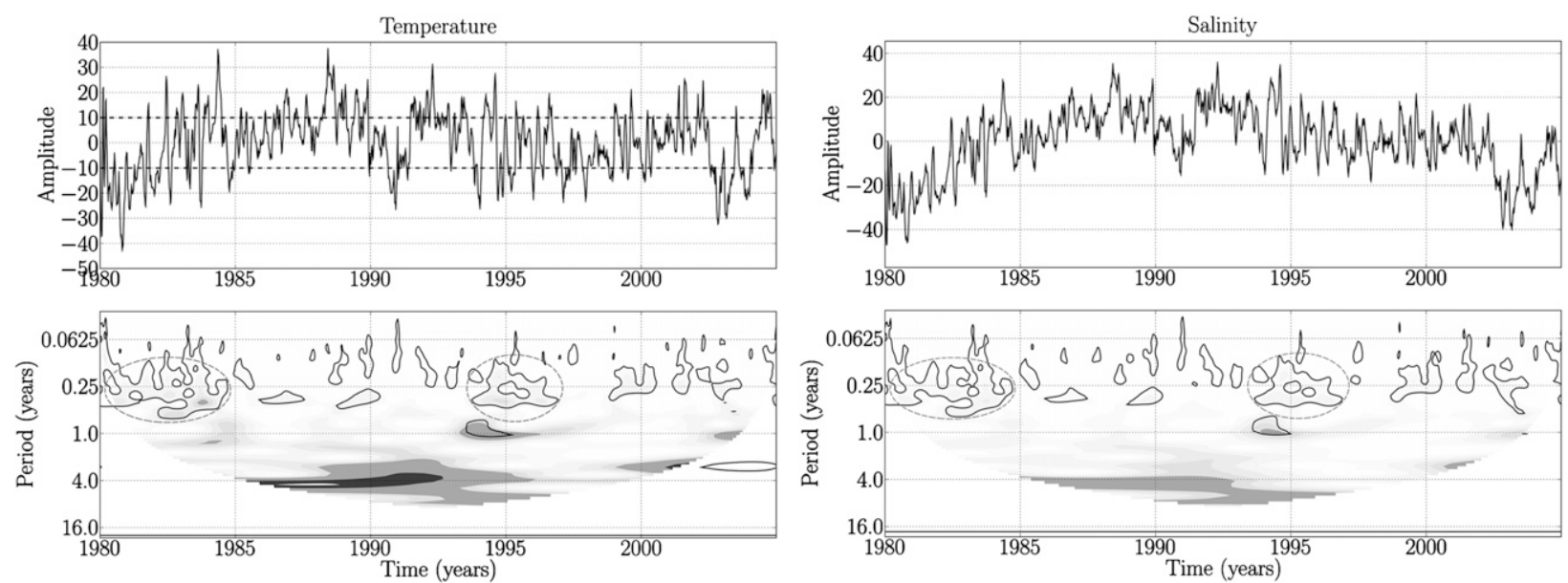

FIG. 5. First EOF temperature and salinity time series (arbitrary units) for (top) the 300-3000-dbar layer and (bottom) their wavelet transforms. The latitude band used ranges from $45^{\circ}$ to $60^{\circ} \mathrm{S}$. The shaded contours are at normalized variances of $0,2,5,10,15,20,50$, and 70. The dashed lines that appear at amplitudes of 10 and -10 on the first EOF temperature time series represent the \pm 0.8 standard deviation threshold chosen for building the composite time series used in the study of positive and negative phases of the pulsation mode.

period, a wavelet transform is applied to the potential temperature and salinity time series (Fig. 5, bottom). We use a Morlet wavelet and a confidence interval relative to a red spectrum. For all plots dealing with wavelet transforms, the thick contour encloses regions of greater than $95 \%$ confidence for a red-noise process whose coefficient has been estimated from the time series following Torrence and Compo (1998). Figure 5 shows a significant frequency of 3-6 months for three periods: 1983-84, 1990, and 1994-96 (see also Sokolov and Rintoul 2003). This is confirmed by Fig. 6, where the power spectrum of the principal component of the first EOF mode for potential temperature is plotted for the years 199196. In this figure, a 0.4-yr period energy peak can be observed and appears as the only significant energy peak in the time series. This analysis suggests that the semiannual frequency observed by Sun and Watts, with their limited temporal sampling, may rather be an intermittent interseasonal signal (frequencies from 3 to 6 months). We note that the interseasonal frequency is significant between 1994 and 1996, which corresponds to several of the years in Sun and Watts's study. It is possible then that Sun and Watts's semiannual frequency (6 months) for the pulsation mode might be due to their very particular time sampling. A notable 4-yr frequency peak for this first EOF is also observable on the two spectra in 1985-95 and 2002-05. This 4-yr period was already observed south of Australia by Sokolov and Rintoul (2003) and was also noticed at a larger scale and attributed to the Antarctic Circumpolar Wave (ACW; White and Peterson 1996). Other analyses also show this frequency (similar to ENSO) but show different spatial and propagative characteristics (Yuan and Martinson 2001).
To summarize thus far, the dominant mode of variability found using the DRAKKAR model output exhibits the same spatial structure as the pulsation mode described by Sun and Watts (2002a). However the frequency content of this mode in the model is far richer than that described by Sun and Watts, whose hydrographic dataset was necessarily limited and irregular in time. Noting that our analysis was carried out at $130^{\circ} \mathrm{E}$, which is west of the WOCE SR3 line at $145^{\circ} \mathrm{E}$, we carried out similar analyses at $120^{\circ}, 140^{\circ}$, and $150^{\circ} \mathrm{E}$, again finding variability with same spatial structure as this pulsation mode. That is, a maximum of variance exists in the same range of density $\left(26.8 \mathrm{~kg} \mathrm{~m}^{-3}<\sigma_{0}<27.3 \mathrm{~kg} \mathrm{~m}^{-3}\right)$ and significant peaks of energy appear at the interseasonal

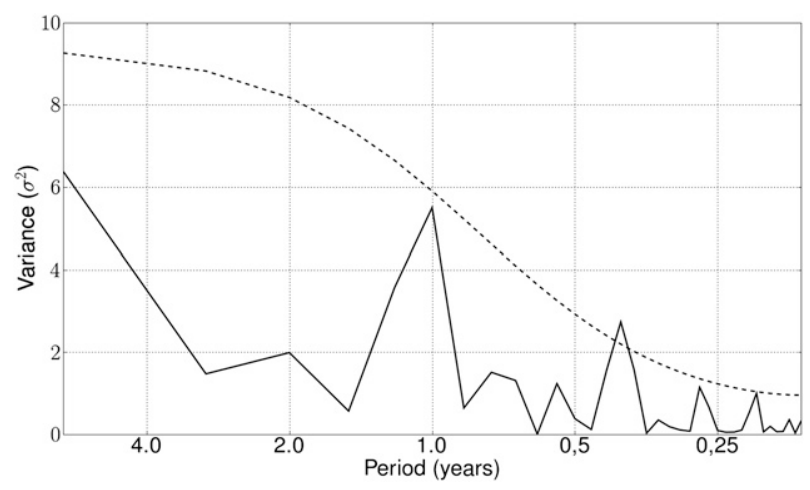

FIG. 6. Power spectrum of the first EOF potential temperature time series computed in streamfunction space for the 300 3000-dbar layer. The dashed line indicates the $95 \%$ confidence interval with respect to red noise estimated from the time series (Torrence and Compo 1998). 


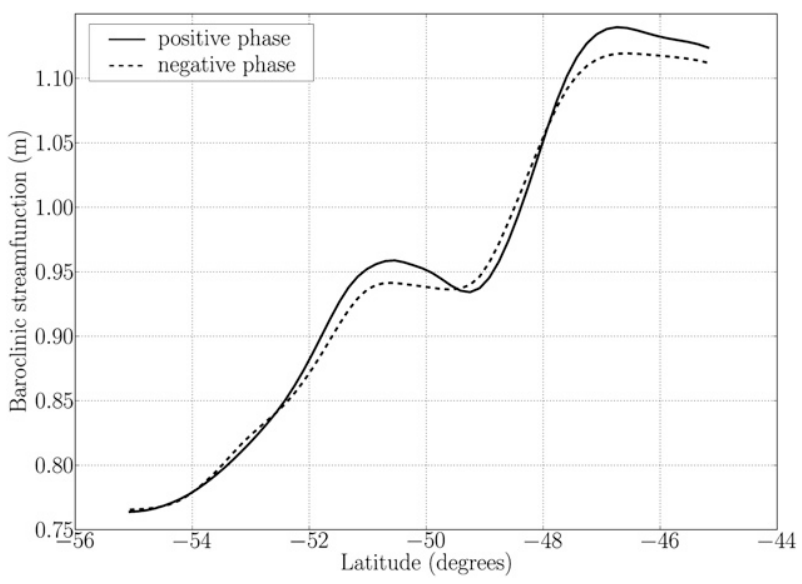

FIG. 7. Baroclinic streamfunction parameter $\left(\phi_{1000-3000}\right)$ plotted against latitude, averaged for all positive phases of the pulsation mode (continuous line) and all negative phases of the pulsation mode (dashed line). Phases are obtained with the composite time series of the pulsation mode (see Fig. 5).

frequency band, suggesting this mode is a typical feature south of Australia.

\section{Relating the pulsation mode to $\mathrm{ACC}$ frontal variability}

\section{a. Limits of the streamfunction projection method}

The streamfunction projection method aims to remove meridional shifts of fronts that are highly energetic along the ACC and thus tend to hide the variability associated with water-mass properties. However, first, the projection is only well defined when $\phi_{1000-3000}$ is a monotonic function of latitude. In fact, in this region of the ACC, there are often reversals in $\phi_{1000-3000}$. Figure 7 shows the composite plots of the baroclinic streamfunction parameter $\phi_{1000-3000}$ corresponding to positive and negative phases of the pulsation mode, respectively, and plotted against latitude. During positive phases, $\phi_{1000-3000}$ is multivalued, with a slope reversal around $50^{\circ} \mathrm{S}$ : that is, between the northern and southern branches of the SAF. This corresponds to either splitting of the SAF or the regular occurrence of a meander or an eddy. Thus, during the positive phase, the temperature-salinity properties to the north of a given $\phi_{1000-3000}$ marking the front can be both cold/fresh and warm/salty. These properties are binned and averaged together in the streamfunction method, leading to spurious variability in water properties, when in fact the underlying cause of the variability could be a shift from a single SAF (negative phase) to multiple occurrences (positive phase).

Second, Sun and Watts sought to reach conclusions about variability in the physical area of waters within the context of the streamfunction projection. However, because the streamfunctions can shift latitudinally and change the meridional distance in the area calculation, the physical volume cannot be assessed, only changes in the vertical thickness. Despite these limitations, the streamfunction projection can and does provide important information about variability in properties relative to the frontal position by removing most of the effects of meridional shifts of the front. It thus seems more relevant to use both the physical and the streamfunction projection spaces to get an accurate and comprehensive view of variabilities.

\section{b. Existence of the pulsation mode in physical space}

The pulsation mode was first described in streamfunction space only, by Sun and Watts (2002a), and a similar mode has been described therein. Because the full model output is available, we can determine the structure of the mode in physical space, specifically whether it corresponds mainly to meandering of the SAF or if it has a truly thermohaline component of variability. To this end, we applied an EOF analysis to potential temperature in the DRAKKAR model without any preliminary projection onto streamfunction space. ${ }^{1}$ The first EOF for potential temperature captures $12.0 \%$ of the subsurface variance (Fig. 8a). Isopycnals $\sigma_{0}=26.8 \mathrm{~kg} \mathrm{~m}^{-3}$ and $\sigma_{0}=27.3 \mathrm{~kg} \mathrm{~m}^{-3}$ in the figure indicate the mean positions of the SAMW and AAIW cores. Three anomalies of opposite sign are located side by side at the SAMW and AAIW interface, between $50^{\circ}$ and $52^{\circ} \mathrm{S}$, corresponding mostly to the southern zone of the SAF.

The pattern of the first EOF of potential temperature is then projected onto the mean streamfunction field to compare it with the pulsation mode pattern described in the previous section (Fig. 4b). This reveals a positive anomaly located in the SAF zone and at the SAMW and AAIW interface, which is the same pattern as that of the pulsation mode.

Composite fields corresponding to positive and negative phases of the pulsation mode are then built from the pulsation mode time series for potential temperature in streamfunction space using an arbitrary threshold of \pm 0.8 standard deviation, based on amplitudes (see Fig. 5). The difference between the potential temperature field in physical space averaged on positive and negative phases of the pulsation mode is plotted in Fig. $8 \mathrm{~b}$. A large part of the variance is located in the SAF zone. Besides this feature, three anomalies of opposite sign are observed in the SAF zone, as already seen in the

\footnotetext{
${ }^{1}$ In what follows, we present results for potential temperature. Similar analyses have also been carried out with salinity.
} 

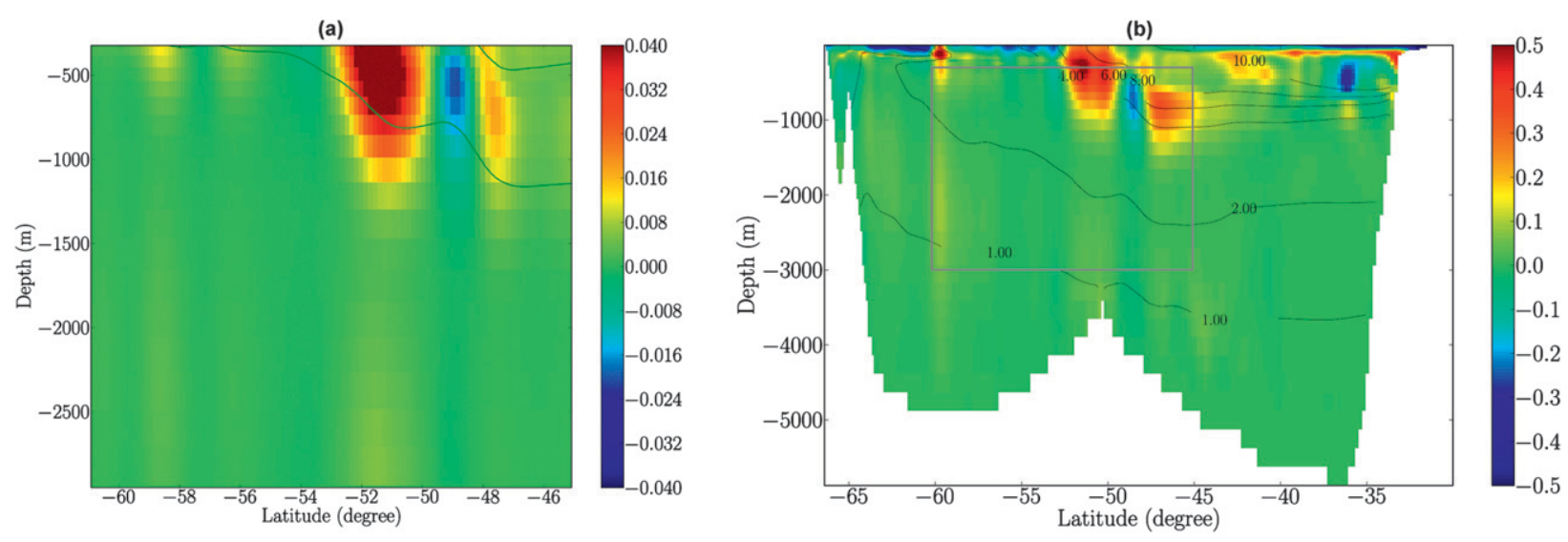

FIG. 8. (a) First EOF of potential temperature field worked out in physical space (arbitrary units). Green lines are isopycnal $\sigma_{0}=$ $26.8 \mathrm{~kg} \mathrm{~m}^{-3}$ (upper line) and isopycnal $\sigma_{0}=27.3 \mathrm{~kg} \mathrm{~m}^{-3}$ (lower line; from DRAKKAR model). (b) Difference between temperature fields in positive phases and negative phases of the pulsation mode. Dark lines correspond to the $1^{\circ}, 2^{\circ}, 4^{\circ}, 6^{\circ}, 8^{\circ}$, and $10^{\circ} \mathrm{C}$ isotherms.

first EOF mode for potential temperature in physical space (Fig. 8a). Thus, the pulsation mode observed in streamfunction space is related to the most energetic pattern of variability in physical space.

A wavelet transform is then applied to the time series of the first EOF mode for potential temperature in physical space. Figure 9 shows a significant interseasonal frequency (3-6 months) for the following periods: 1980 85, 1990-92, 1995-96, and 1999-2001. A 4-yr frequency is also found to be significant. Both frequency bands were shown above to characterize the pulsation mode.

However, the time series of the first EOF mode for potential temperature in physical space and streamfunction space do not appear to be well-correlated at first sight. First of all, the wavelet transform is much more complex in physical space than in streamfunction space. That is, the streamfunction projection does indeed filter out a large part of thermohaline variability associated with ACC frontal motion. The additional frequencies that can be observed in physical space case are thus mainly associated with ACC frontal variability. In particular, annual frequency peaks in physical space are not observed in streamfunction space.

Second, the additional signal that sometimes appears in streamfunction space can probably be explained by the limitations of the projection, rather than by intrinsic thermohaline variability on either side of the SAF. Because the baroclinic streamfunction is nonmonotonic in latitude, different water masses can be artificially mixed, creating a spurious anomaly. This slope inversion seems to occur quite often, so artificial signals may appear on the streamfunction space wavelet transform that do not exist in physical space. The pulsation mode therefore probably accounts for the dominant part of the variance in physical space as well, with ACC frontal variability reducing the fraction of variance it accounts for in physical space.

To summarize, the first EOF mode of potential temperature in physical space shows the same main features as the pulsation mode obtained in streamfunction space. Both have maximum variance at the SAMW and AAIW interface in the SAF zone. Both have intermittent interseasonal energy and 4-yr energy. The same analysis was also undertaken for salinity (Figs. 4d, 9; EOF pattern in physical space not shown), with the same conclusions. Thus, the pulsation mode is manifested in both streamfunction and physical spaces.

\section{c. Description of the pulsation mode in physical space}

To better describe the pulsation mode in physical space, we analyze events occurring during the positive and negative phases of the first EOF mode obtained in physical space. In what follows, we present results obtained during two typical positive and negative phase events picked up during the same season. Potential temperature cross sections are plotted for 17 August 1980 (a typical winter positive phase event) and for 13 August 1993 (a typical winter negative phase event) in Fig. 10. During the negative phase of the mode, the isopycnals are relatively smooth. During the positive phase, on the other hand, the isopycnals become strongly modified: they tighten and their slopes become more vertical. There is also a large uplift/downlift of isopycnals at about $48^{\circ}-52^{\circ} \mathrm{S}$. At this section at $130^{\circ} \mathrm{E}$, this bump is located on the north side of the Southeast Indian Ridge, which runs parallel to the ACC south of Australia. The feature could be either a SAF meander or an eddy located just on the northern flank of the ridge. On either side of the isopycnal feature, two weakly stratified water masses 

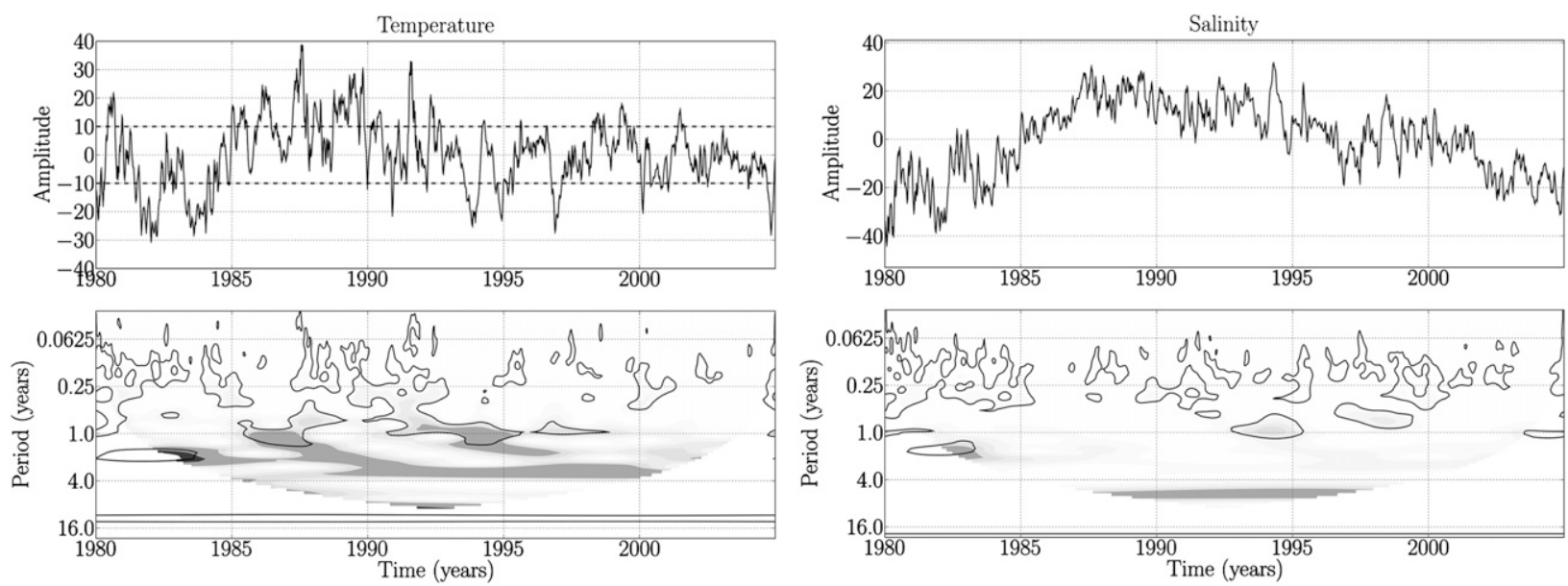

FIG. 9. First EOF temperature and salinity time series (arbitrary units) carried out in physical space for (top) the 300-3000-dbar layer and (bottom) their wavelet transforms. The shaded contours are at normalized variances of $0,2,5,10,15,20,50$, and 70. The dashed lines that appear at amplitudes of 10 and -10 on the first EOF temperature time series represent the \pm 0.8 standard deviation threshold chosen for building the composite time series used in the study of positive and negative phases of processes in physical space (section 4b).

are present, with temperature ranging from $8^{\circ}$ to $10^{\circ} \mathrm{C}$, corresponding to southeast Indian SAMW properties.

Therefore, we have illustrated that the pulsation mode can be associated with the intermittent occurrence of an uplift-downlift of isopycnals in physical space, which can even change the slope of the streamfunction parameter (see Fig. 7). We further stress that the uplift-downlift pattern of isopycnals is consistent with the thermohaline variations diagnosed in physical space.
To summarize, diagnostics carried out in physical space show that the pulsation mode defined in streamfunction space is linked with SAF variability in physical space and that the thermohaline anomaly associated with this mode is related to an uplift/downlift of isopycnals located on the northern flank of the Southeast Indian Ridge. Frontal movements such as splitting, meandering, or eddying are not filtered by the streamfunction projection, which suggests that the pulsation mode might mostly be due to such
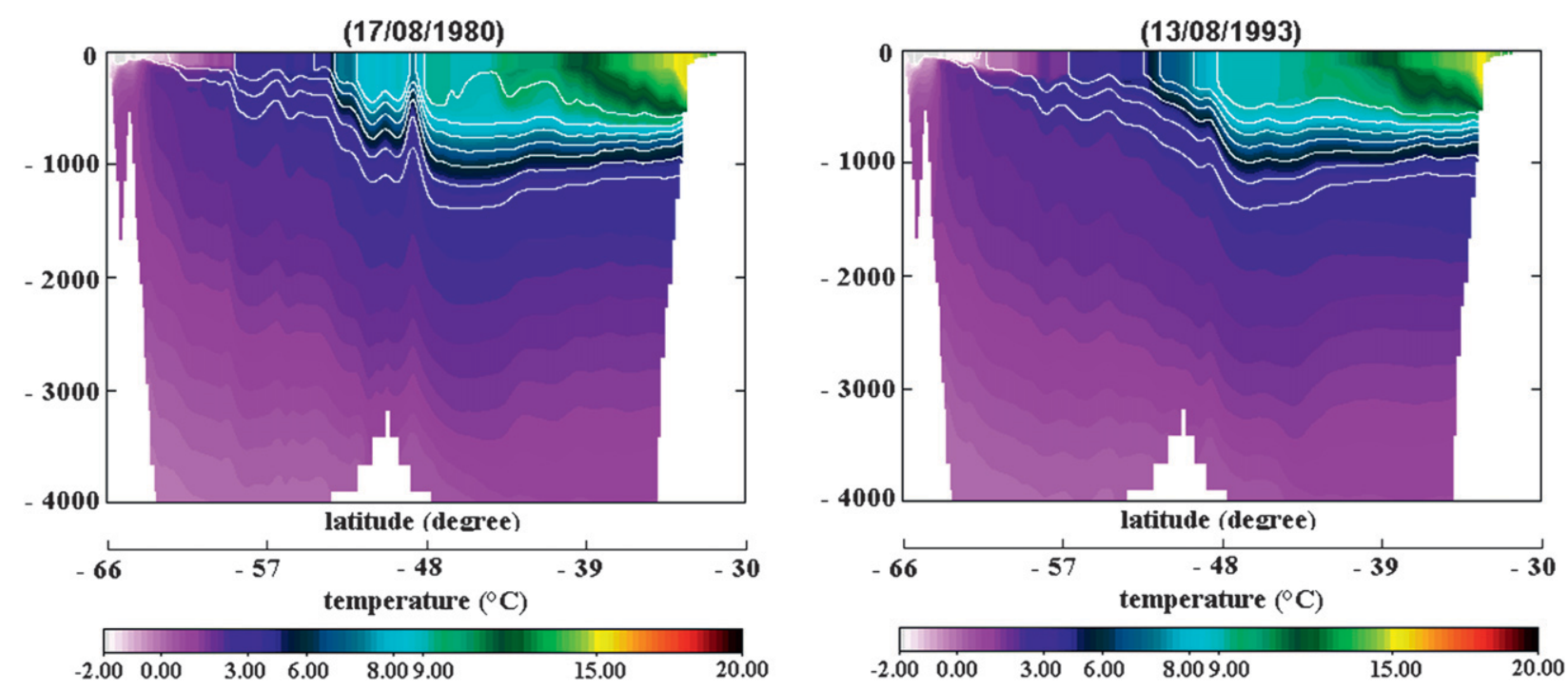

FIG. 10. Potential temperature snapshots during (left) a typical positive phase of the pulsation mode and (right) a typical negative phase of the pulsation mode. White lines indicate isopycnals ranging from $\sigma_{0}=26.8 \mathrm{~kg} \mathrm{~m}^{-3}$ to $\sigma_{0}=27.4 \mathrm{~kg} \mathrm{~m}^{-3}$ with a $0.1 \mathrm{~kg} \mathrm{~m}^{-3} \mathrm{contour}$ interval. 

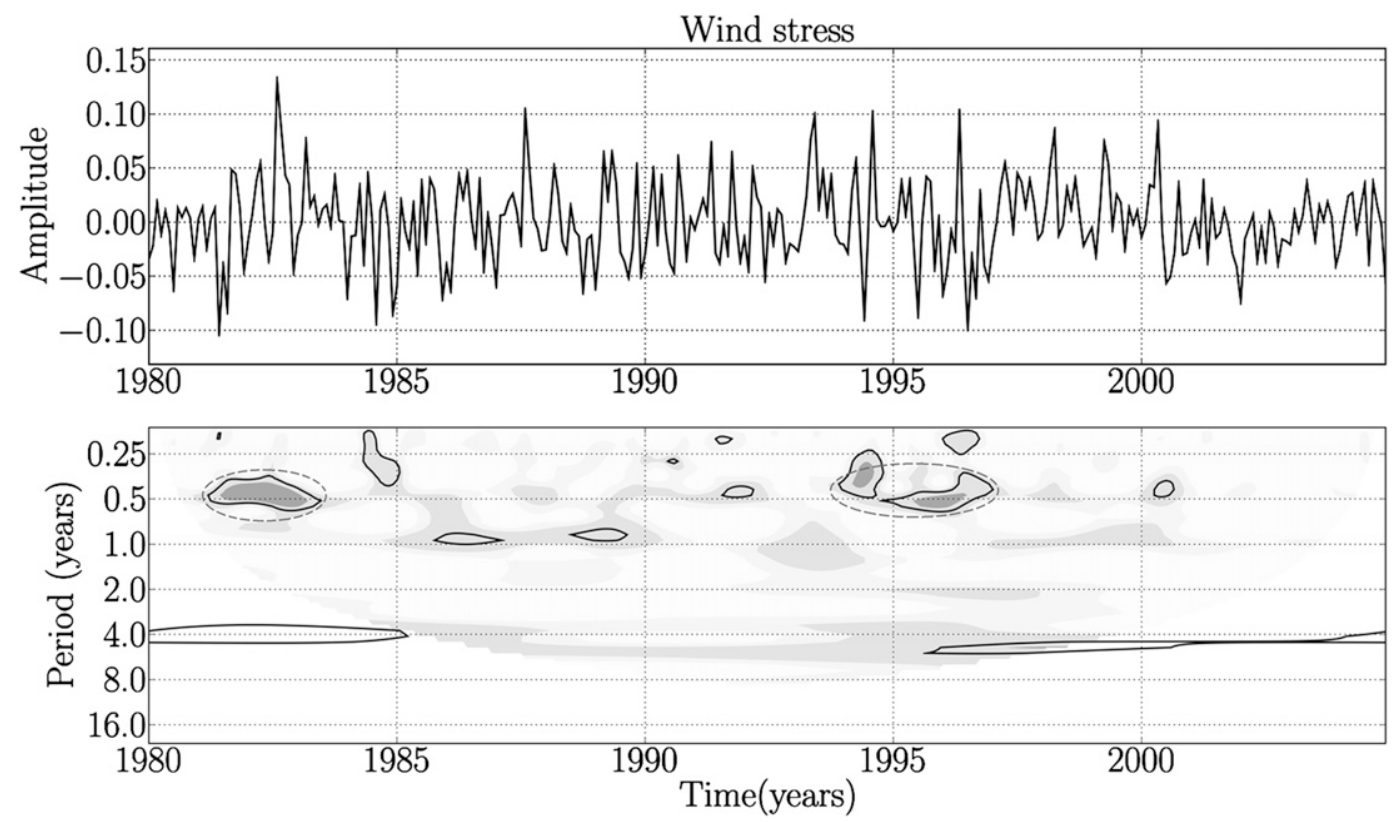

FIG. 11. (top) Time series and (bottom) wavelet transform of wind stress averaged within a square of $120^{\circ}-160^{\circ} \mathrm{E}$ and $45^{\circ}-60^{\circ} \mathrm{S}$ (from ERA-40). The wind stress amplitude units are $\mathrm{kg} \mathrm{s}^{-2} \mathrm{~m}^{-1}$. The shaded contours are at normalized variances of $0,1,2,5,10$, and 15 .

physical variability rather than intrinsic thermohaline variability.

\section{Origin of the pulsation mode}

In this section, the origin of the pulsation mode is examined with a focus on the meridional transect at $130^{\circ} \mathrm{E}$. Preliminary analyses along a few other meridional sections south of Australia are largely consistent. The Sun and Watts hypotheses of forcing of the pulsation mode by westerly winds and barotropic transport advection are first tested and are not found to be supported by the model output. Instead, we find that the pulsation mode displays many similarities with cold-core eddy events.

\section{a. Assessing the hypotheses of Sun and Watts (2002a)}

\section{1) RELATION OF THE PULSATION MODE TO WESTERLY WINDS}

In Sun and Watts (2002a), there was a convincingly strong visual correlation between the westerly wind cycle and the phase of the pulsation mode, dominated by the semiannual passage of the westerly wind maximum over the location of the SAF. Based on this, they hypothesized that changes in cross-SAF Ekman transport and in the barotropic transport of the SAF created the thermohaline variability in the pulsation mode.

Here, we assess this mechanism in the model. The monthly westerly wind stress is averaged within the region $45^{\circ}-60^{\circ} \mathrm{S}, 120^{\circ}-160^{\circ} \mathrm{E}$, using the model forcing dataset (ERA-40). The wind stress time series obtained and its wavelet transform are plotted in Fig. 11. The interseasonal frequency band has significant energy during two periods, 1982-83 and 1994-96, which coincide with the periods when the pulsation mode also holds some energy in the same frequency band. However, there was no clear visual relation between the pulsation mode and the westerly wind time series, unlike in Sun and Watts (2002a). We could also not reproduce from the model output the strong semiannual signal in the pulsation mode seen by Sun and Watts (2002a). Neither the annual frequency peak nor the 4-yr peak, which are present on both time series, appear during the same years for the two time series. This may mean that the pulsation mode and the westerly wind variability are phase shifted; indeed, the lower the signal frequency is, the greater the phase shift should be. To conclude, we cannot exclude the hypothesis of wind forcing, but documenting this further will require additional analysis.

\section{2) NATURE OF THERMOHALINE VARIATIONS ASSOCIATED WITH THE PULSATION MODE}

The inverse method developed by Bindoff and McDougall (1994) is used here to diagnose the physical origin of the observed variations. This method assumes that changes in atmospheric forcing can affect the subsurface water column by only three processes, which have 
very distinctive thermohaline signatures: pure warming ${ }^{2}$ at constant depth, pure freshening at constant depth, or pure heaving. These three processes have different signatures in temperature and salinity fields, at constant depth and on neutral surfaces. Following the method, it is possible to use these signatures to estimate the relative strengths of each process in a given domain, provided one can define two states from the hydrography. For Bindoff and McDougall (1994), these corresponded to two hydrographic sections at different times. Here, given the continuous time series of the model output, we define the states based on the first EOF in physical space of the coupled variables $\alpha \times \theta$ and $\beta \times S$. The two states are defined by adding and substracting the first EOF anomalies to the mean potential temperature and salinity fields. This first EOF mode was shown earlier in section 4 to be the pulsation mode. A linear system based on the three processes (i.e., pure warming, pure freshening, and pure heaving) is then built for each point of the section. The linear system being underconstrained, one needs to formulate some additional hypothesis to find a unique solution to the problem. Here, we choose to use the "single process" hypothesis suggested by Bindoff and McDougall (1994): namely, the solution is sought successively as the contribution of only one of the three processes instead of a linear combination of the three processes. Then, the part of variance explained by each of the three processes under a single process hypothesis is averaged on potential density surfaces in physical space.

The percentage of variance explained by pure warming, pure freshening, or pure heaving for a given class of density is plotted in Fig. 12. The pure-warming process largely dominates variability for densities lighter than $\sigma_{0}=27.3 \mathrm{~kg} \mathrm{~m}^{-3}$, explaining about $90 \%$ of the variability. The spatial pattern of the part of variance explained by each process (not shown) also reveals that the pure warming dominates. Physically, subsurface waters are mostly warmer or cooler at constant depth at the SAMW and AAIW interface. This result can be linked to the spatial pattern of the EOF (Fig. 8a): two positive anomalies surrounding a negative anomaly in the positive phase of the pulsation mode. Thus, during the positive phase of the pulsation mode, this pure-warming process corresponds to a cooling just north of the Southeast Indian Ridge and to a warming for surrounding water masses.

\footnotetext{
2 In what follows, we use Bindoff and McDougall's (1994) terminology so that pure warming actually refers to the subsurface thermohaline signature after subduction of a surface change in temperature only. Similarly, pure freshening refers to the signature at some depth of a surface change in salinity only.
}

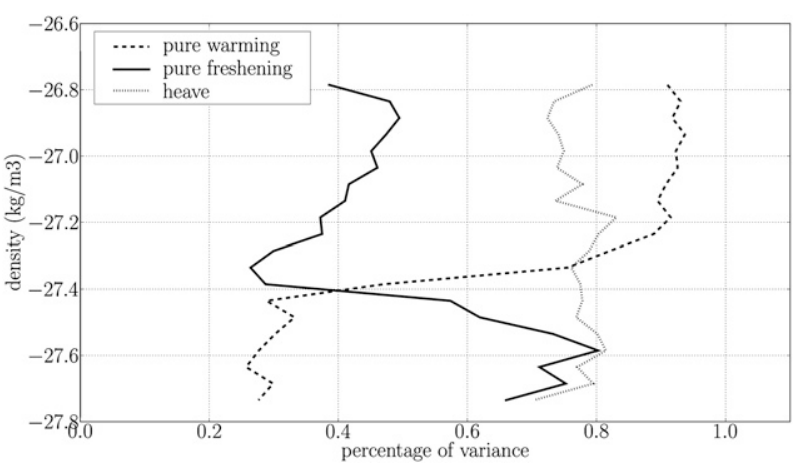

FIG. 12. Application of Bindoff and McDougall's (1994) method on the leading EOF fields computed in physical space. Each plot represents the percentage of variance explained by the corresponding process for a class of density: that is, pure warming, pure freshening, and heave. The calculation of the variance of each process is based on the single-process hypothesis explained by Bindoff and McDougall (1994) in section 5b of their paper. The latitude band used ranges from $45^{\circ}$ to $60^{\circ} \mathrm{S}$.

The variability due to heaving is quite constant and rather large for $\sigma_{0}=26.8-27.8 \mathrm{~kg} \mathrm{~m}^{-3}$. Moreover, the heaving process dominates for densities greater than $\sigma_{0}=27.3 \mathrm{~kg} \mathrm{~m}^{-3}$, explaining between $75 \%$ and $80 \%$ of the variations. Pure freshening explains a significant part of the variance only for denser waters $\left(\sigma_{0}>27.4 \mathrm{~kg} \mathrm{~m}^{-3}\right)$ in a narrow density class centered at $\sigma_{0}=27.6 \mathrm{~kg} \mathrm{~m}^{-3}$, where heaving is also important. This corresponds to the CDW, where Sun and Watts (2002a) also found a local maximum of salinity change during positive phases of the pulsation mode. They furthermore hypothesized that this deep thermohaline change was due to anomalous zonal advection of salt because of an increased ACC barotropic transport in positive phases of the pulsation mode. Here, Fig. 12 clearly shows that one cannot rule out the contribution of heaving to thermohaline changes in the deep layers. This rather simple explanation for thermohaline changes in the deep layers is also consistent with Fig. 10 (left) where, during positive phases of the pulsation mode, the isopycnal uplift above the northern flank of the ridge can be traced down to the deepest layers. In fact, as will be shown in the following section, this explanation of deep layer salinity changes being mostly due to heaving is also one of the conclusions of Morrow et al. (2004). Variations in the deepest waters thus probably correspond to the vertical displacement of isotherms and isohalines, without changes of water masses, which are likely due to the adjustment to the changes in the subsurface waters. ${ }^{3}$

\footnotetext{
${ }^{3}$ Variations in the deepest waters might also be caused by changes in wind stress or changes in Ekman pumping at the surface.
} 

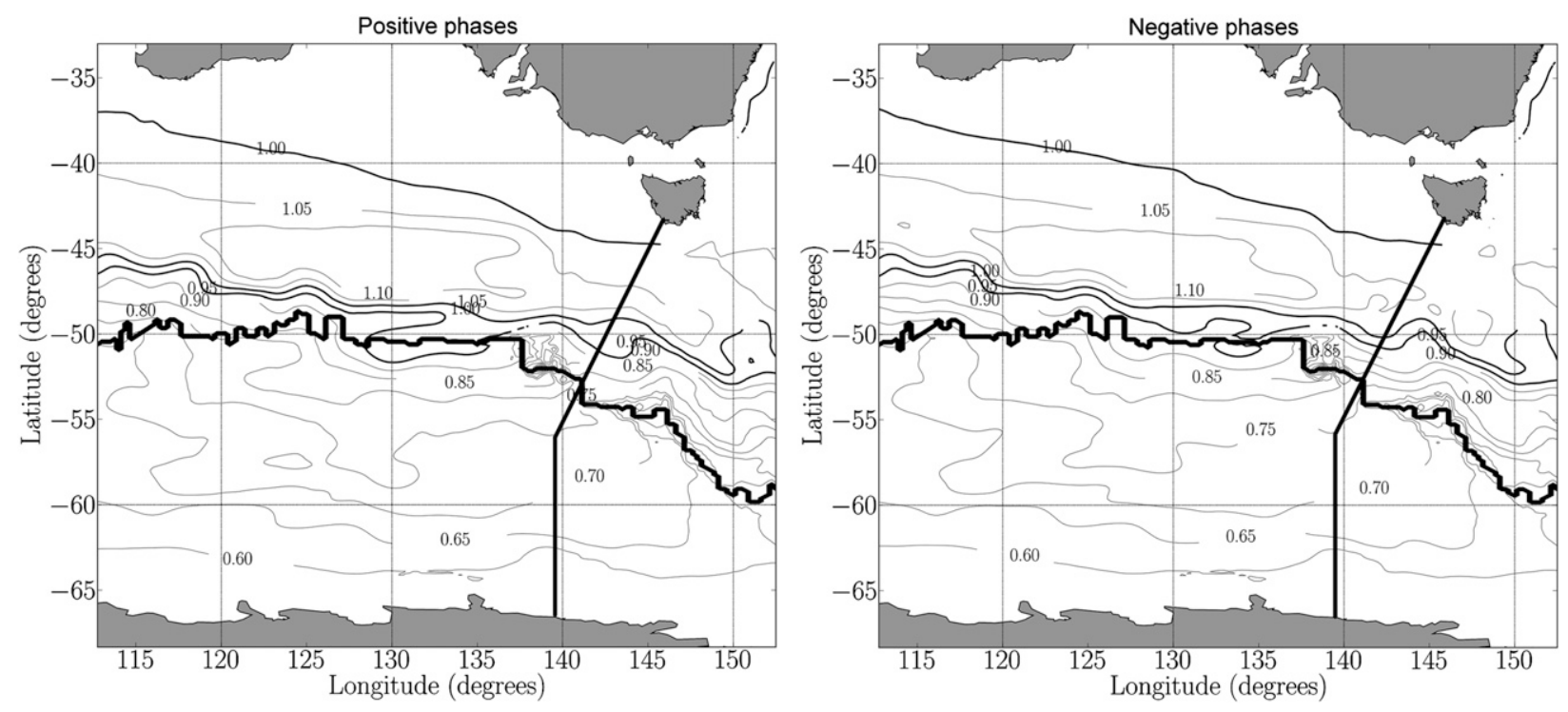

FIG. 13. Baroclinic streamfunction parameter $\left(\phi_{1000-3000}\right)$ isolines south of Australia averaged for (left) all positive phases and (right) all negative phases obtained with the composite time series of the first EOF temperature in physical space (see Fig. 9). Isolines $\phi_{1000-3000}=1.0$ and $0.95 \mathrm{~m}$ are drawn thicker than the others. The thick dark sinuous contour indicates the Southeast Indian Ridge crest. The black straight line indicates the location of the WOCE SR3 line.

Sun and Watts (2002a) hypothesized that variance in the CDW is due to barotropic transport changes forced by changes in the westerly winds. We do see a clear correspondence between the westerly wind variations and barotropic transport as shown by Hughes et al. (1999) with, in particular, increased winds and transport in both March and August (not shown). However, the barotropic transport changes are not significantly correlated with the pulsation mode time series, suggesting that salinity changes at the CDW levels are not straightforwardly related to ACC transport variations.

Finally, if the EOF analysis is carried out in the baroclinic streamfunction space, we saw previously (see section 4 a) that nothing consistent can be said regarding water-mass volume variability. Then, the Sun and Watts hypothesis regarding linkage of westerly winds and hence variable convergence/sinking of water masses via Ekman transport changes could be considered arguable and requires some further analysis.

\section{b. A new perspective on the pulsation mode origin}

The region south of Australia has been shown to be an area of growing eddy energy (Philipps and Rintoul 2000). The SAF is subject here to strong mesoscale variability in the form of meanders and transient eddies. These transient eddies play a major role in transferring salt or freshwater across the ACC fronts. Among those eddies, cold-core eddies transport cool, low-salinity water across the SAF into the subantarctic zone where mode and intermediate waters form. Therefore, we assess the hypothesis of a pulsation mode being associated with a cold-core eddy event, as described in Morrow et al. (2004).

To observe the events associated with the different phases of the pulsation mode in the $130^{\circ} \mathrm{E}$ region, composite fields corresponding to positive and negative phases of the pulsation mode are then built from the first EOF time series for potential temperature in physical space using an arbitrary threshold of \pm 0.8 standard deviation, based on amplitudes (see Fig. 9). Isolines of the baroclinic streamfunction south of Australia are plotted for all positive and negative phases in Fig. 13. During the positive phase of the pulsation mode, isoline $\phi_{1000-3000}=$ $0.95 \mathrm{~m}$ exhibits a large meander located over the peak of the Southeast Indian Ridge. We cannot distinguish whether the anomalous pattern is a recurrent meander or an eddy. Moreover, if Fig. 13 seems to clearly show a meander, Fig. 10 suggests the presence of an eddy blocked by the northern flank of the Southeast Indian Ridge. During the negative phase, no loop in the baroclinic streamfunction is observed and the SAF seems to narrow, situated just north of the ridge topography. In addition, we have already shown (section 4) a local minimum of the baroclinic streamfunction, indicative of recirculation, between $49^{\circ}$ and $50^{\circ} \mathrm{S}$ during the positive phase (Fig. 7), corresponding to an isopycnal uplift on the northern flank of the Southeast Indian Ridge (Fig. 10). The uplift is roughly $100 \mathrm{~km}$ wide and shifts cold freshwater toward the surface and in particular into the mode waters. Further, this uplift of cold fresh waters also induces warm salty waters to be advected south of the 
cold-core pattern from $1^{\circ}$ or $2^{\circ}$ (Fig. 10). Here, we note again that this warm advection may correspond to either the export of warm salty waters to the south by a meander (see also Fig. 13) or the southward movement of warm salty waters as a result of the cool freshwater upward input. Moreover, this observation is consistent with the presence of warm anomalies both in the subsurface EOF analysis in physical space (Fig. 8) and in the physical processes analysis using Bindoff and McDougall's method (Fig. 12). Therefore, the location, size, and pattern of the pulsation mode match the cold-core eddy pattern identified by Morrow et al. (2004) south of Tasmania.

Morrow et al. (2004) observed that many individual eddies were spawned in the 1993-96 period (see also Rintoul et al. 1997) but relatively few in the 1997-2000 period, which also coincides with the pulsation mode being relatively active during the 1994-96 period, as Sun and Watts found as well. Furthermore, the Morrow et al. (2004) study reveals that, on average, two cold-core eddies separate from the SAF south of Tasmania each year. This result clearly matches with the description of an intermittent and interseasonal pulsation mode.

Finally, plotting temperature and salinity anomalies against potential density surfaces, Morrow et al. (2004) found that the temperature and salinity anomalies extended from the surface down to $\sigma_{0}=27.3 \mathrm{~kg} \mathrm{~m}^{-3}$; in contrast, below $\sigma_{0}=27.3 \mathrm{~kg} \mathrm{~m}^{-3}$, the anomalies were mainly due to the heaving of isopycnals. We note again that this result is in total agreement with our analysis using Bindoff and McDougall's method (Fig. 12).

We thus suggest that the positive phase of the pulsation mode might correspond to cold-core eddy events. The Southeast Indian Ridge plays a role by steering the ACC and affecting eddy formation (Rintoul et al. 1997; Morrow et al. 2004; Sallée et al. 2008). In particular, Morrow et al. (2004) showed that cold-core eddies could contribute to a freshening and a cooling of the SAMW formed north of the front. Thus, we suggest that the linkage of the pulsation mode to SAMW thermohaline properties could be through cold-core eddy formation rather than through Ekman transport changes. To fully validate the hypothesis of the pulsation mode resulting from cold-core eddy formation, further investigations are required and in particular a sea level anomaly analysis over time would be an efficient way to determine the nature of the pattern.

\section{Summary and conclusions}

A 25-yr potential temperature and salinity dataset, provided by an eddy-admitting global circulation model forced by atmospheric reanalyses, is used to analyze oceanic variability in the subsurface waters (300-3000 dbar) south of Australia. The dominant pattern of variability in both physical space and in a projection to baroclinic streamfunction space is located at the SAMW and AAIW interface within the SAF. The spatial pattern of the first EOF strongly resembles the pattern of variability described by Sun and Watts (2002a) for this region, which they called the pulsation mode. A wavelet transform reveals significant interseasonal frequency (3-6 months) for three periods, 1983-84, 1990, and 1994-96, which shows that this mode of variability is not intrinsically associated with a semiannual frequency, as Sun and Watts's study suggested. A low-frequency (4 yr) peak for this dominant EOF is also noted.

The projection of temperature and salinity to baroclinic streamfunction space was shown to only filter out meridional shifts of fronts but not motions associated with front splitting, meanders, or eddies. In physical space, the dominant EOF exhibits the same spatial and temporal characteristics as the pulsation mode identified in streamfunction space and is associated with a meandering or eddying feature of the SAF located on the northern flank of the Southeast Indian Ridge.

Physical processes responsible for the pulsation mode were then investigated. There was no clear correlation between the pulsation mode and westerly wind stress variability, unlike the results shown by Sun and Watts (2002a) that were based on limited hydrographic section sampling. Using Bindoff and McDougall's (1994) method for separating variability due to temperature, salinity, and heave, we found that a pure-heave mechanism is likely to explain the variations below AAIW in the deepest layers, whereas a "pure warming" process can account for the positive anomaly observed between SAMW and AAIW during positive phases of the pulsation mode. This implies that barotropic transport advection cannot be the main cause of the origin of the pulsation mode and that a southward shift of warm waters occurs during a positive phase of the pulsation mode. Finally, comparing the pulsation mode characteristics with cold-core eddies as described by Morrow et al. (2004), it is suggested that positive phases of the pulsation mode may correspond to cold-core eddy events. Thus, the pulsation mode might impact SAMW properties by injecting eddies carrying cold freshwater into the SAMW formation zone rather than through anomalous northward Ekman transport as suggested by Sun and Watts (2002a). If the hypothesis of the pulsation mode corresponding to a cold-core eddy event holds true, our diagnostics offer a complementary view on cold-core eddy events. This study therefore demonstrates that much can be learned from the joint use of observations and model output. 
Acknowledgments. Financial support from the CNRS through the LEFE-IDAO program is gratefully acknowledged. Technical support by J. M. Molines was also much appreciated. Simulations with the ORCA025 model were carried out at the CNRS IDRIS super computer facility in Orsay. For this project, C. O. Dufour was partially supported by the French CEA (Commissariat à l'Energie Atomique). J. Le Sommer, T. Penduff, and B. Barnier are supported by the French Centre National de la Recherche Scientifique (CNRS). M. H. England is supported by the Australian Research Council and Australia's Antarctic Science Program.

We thank the two reviewers for their valuable and constructive comments, particularly for their contribution to the discussion on the origin of the pulsation mode, which helped to improve an earlier version of this manuscript. The authors are grateful to L. D. Talley for her help in reformulating earlier versions of the manuscript. C. Langlais is also acknowledged for her useful advice concerning the definitions of ACC fronts in model simulations.

\section{REFERENCES}

Banks, H., R. Wood, and J. Gregory, 2002: Changes to Indian Ocean Subantarctic Mode Water in a coupled climate model as $\mathrm{CO}_{2}$ forcing increases. J. Phys. Oceanogr., 32, 2816-2827.

Barnier, B., and Coauthors, 2006: Impact of partial steps and momentum advection schemes in a global ocean circulation model at eddy-permitting resolution. Ocean. Dyn., 56, 543-567, doi:10.1007/s10236-006-0082-1.

Belkin, I., and A. Gordon, 1996: Southern Ocean fronts from the Greenwich Meridian to Tasmania. J. Geophys. Res., 101, 3675-3696.

Biastoch, A., C. W. Böning, J. Getzlaff, J. Molines, and G. Madec, 2008a: Causes of interannual-decadal variability in the meridional overturning circulation of the midlatitude North Atlantic Ocean. J. Climate, 21, 6599-6615.

,-- , and J. R. E. Lutjeharms, 2008b: Agulhas leakage dynamics affects decadal variability in Atlantic overturning circulation. Nature, 456, 489-492.

— J. R. E. Lutjeharms, C. W. Böning, and M. Scheinert, 2008c: Mesoscale perturbations control inter-ocean exchange south of Africa. Geophys. Res. Lett., 35, L20602, doi:10.1029/ 2008 GL035132.

Bindoff, N. L., and T. J. McDougall, 1994: Diagnosing climate change and ocean ventilation using hydrographic data. J. Phys. Oceanogr., 24, 1137-1152.

Brodeau, L., B. Barnier, A.-M. Treguier, T. Penduff, and S. Gulev, 2010: An ERA40-based atmospheric forcing for global ocean circulation models. Ocean Modell., 31, 88-104.

Bromwich, D. H., and R. L. Fogt, 2004: Strong trends in the skill of the ERA-40 and NCEP-NCAR reanalyses in the high and midlatitudes of the Southern Hemisphere, 1958-2001. J. Climate, 17, 4603-4619.

Cai, W., and P. G. Baines, 1996: Interactions between thermohalineand wind-driven circulations and their relevance to the dynamics of the Antarctic Circumpolar Current, in a coarse-resolution global ocean general circulation model. J. Geophys. Res., 101, 73-93.

Dell'Aquila, A., P. M. Ruti, S. Calmanti, and V. Lucarini, 2007: Southern Hemisphere midlatitude atmospheric variability of the NCEP-NCAR and ECMWF reanalyses. J. Geophys. Res., 112, D08106, doi:10.1029/2006JD007376.

DRAKKAR Group, 2007: Eddy-permitting ocean circulation hindcasts of past decades. CLIVAR Exchanges, No. 12, International CLIVAR Project Office, Southampton, United Kingdom, 8-10.

Flament, P., 2002: A state variable for characterizing water masses and their diffusive stability: Spiciness. Prog. Oceanogr., 54, 493-501.

Georgi, D. T., 1979: Modal properties of Antarctic Intermediate Water in the southeast Pacific and the South Atlantic. J. Phys. Oceanogr., 9, 456-468.

Gille, S. T., 1994: Mean sea surface height of the Antarctic Circumpolar Current from Geosat data: Method and application. J. Geophys. Res., 99, 255-273.

— D. P. Stevens, R. T. Tokmakian, and K. J. Heywood, 2001: Antarctic Circumpolar Current response to zonally averaged winds. J. Geophys. Res., 106, 2743-2759.

Gordon, A., H. Taylor, and D. Georgi, 1977: Antarctic oceanographic zonation. Polar Oceans, M. J. Dunbar, Ed., Arctic Institute of North America, 45-76.

Hertzog, A., C. Basdevant, and F. Vial, 2006: An assessment of ECMWF and NCEP-NCAR reanalyses in the Southern Hemisphere at the end of the presatellite era: Results from the EOLE experiment (1971-72). Mon. Wea. Rev., 134, 3367-3383.

Hughes, C., M. Meredith, and K. Heywood, 1999: Wind-driven transport fluctuations through Drake Passage: A southern mode. J. Phys. Oceanogr., 29, 1971-1992.

Killworth, P., 1992: An equivalent-barotropic mode in the Fine Resolution Antarctic Model. J. Phys. Oceanogr., 22, 1379-1387.

Koch-Larrouy, A., R. Morrow, T. Penduff, and M. Juza, 2010: Origin and mechanism of Sub Antarctic Mode Water formation and transformation in the Southern Ocean. Ocean Dyn., 60, 563-583.

Le Sommer, J., T. Penduff, S. Theetten, G. Madec, and B. Barnier, 2009: How momentum advection schemes influence currenttopography interactions at eddy permitting resolution. Ocean Modell., 29, 1-14.

Lique, C., A.-M. Treguier, M. Scheinert, and T. Penduff, 2009: A model-based study of ice and freshwater transport variabilities along both sides of Greenland. Climate Dyn., 33, 685-705.

Lombard, A., G. Garric, and T. Penduff, 2009: Regional patterns of observed sea level change: Insights from a $1 / 4^{\circ}$ global ocean/ sea-ice hindcast. Ocean Dyn., 59, 433-449.

Lübbecke, J., C. W. Böning, and A. Biastoch, 2008: Variability in the subtropical-tropical cells and its effect on near-surface temperature of the equatorial Pacific: A model study. Ocean Sci., 4, 73-88.

Madec, G., 2008: Nemo ocean engine. Institut Pierre-Simon Laplace Note du Pole de Modelisation 27, 1288-1619.

Metzl, N., B. Tilbrook, and A. Poisson, 1999: The annual $f \mathrm{CO}_{2}$ cycle and the air-sea $\mathrm{CO}_{2}$ flux in the sub-Antarctic Ocean. Tellus, 51B, 849-861.

Morrow, R., J.-R. Donguy, A. Chaigneau, and S. R. Rintoul, 2004: Cold-core anomalies at the Subantarctic Front, south of Tasmania. Deep-Sea Res. I, 51, 1417-1440.

Orsi, A. H., T. Whitworth, and W. D. Nowlin Jr., 1995: On the meridional extent and fronts of the Antarctic Circumpolar Current. Deep-Sea Res. I, 42, 641-673. 
Penduff, T., M. Juza, L. Brodeau, G. C. Smith, B. Barnier, J.-M. Molines, A.-M. Treguier, and G. Madec, 2010: Impact of global ocean model resolution on sea-level variability with emphasis on interannual time scales. Ocean Sci., 6, 269-284.

Philipps, H., and S. Rintoul, 2000: Eddy variability and energetics from direct current measurements in the Antarctic Circumpolar Current south of Australia. J. Phys. Oceanogr., 30, 3050-3076.

Renner, A., K. Heywood, and S. Thorpe, 2009: Validation of three global ocean models in the Weddell Sea. Ocean Modell., 30,1-15.

Rintoul, S., J. Donguy, and D. Roemmich, 1997: Seasonal evolution of upper ocean thermal structure between Tasmania and Antarctica. Deep-Sea Res. I, 44, 1185-1202.

Sallée, J.-B., K. Speer, and R. Morrow, 2008: Response of the Antarctic Circumpolar Current to atmospheric variability. J. Climate, 21, 3020-3039.

Sloyan, B., and S. R. Rintoul, 2001: The Southern Ocean limb of the global deep overturning circulation. J. Phys. Oceanogr., 31, 143173.

Sokolov, S., and S. R. Rintoul, 2002: Structure of Southern Ocean fronts at $140^{\circ}$ E. J. Mar. Syst., 37, 151-184.

$\longrightarrow$, and - 2003: Subsurface structure of interannual temperature anomalies in the Australian sector of the Southern Ocean. J. Geophys. Res., 108, 3285, doi:10.1029/2002JC001494. , and _ 2007a: Multiple jets of the Antarctic Circumpolar Current south of Australia. J. Phys. Oceanogr., 37, 1394-1412.

— and - 2007b: On the relationship between fronts of the Antarctic Circumpolar Current and surface chlorophyll concentrations in the Southern Ocean. J. Geophys. Res., 112, C07030, doi:10.1029/2006JC004072.

Speer, K., S. R. Rintoul, and B. Sloyan, 2000: The diabatic Deacon cell. J. Phys. Oceanogr., 30, 3212-3222.

Sun, C., and D. R. Watts, 2001: A circumpolar gravest empirical mode for the Southern Ocean hydrography. J. Geophys. Res., 106, 2833-2856.

— cumpolar Current south of Australia. J. Phys. Oceanogr., 32, 1479-1495.

— , and $-2002 \mathrm{~b}$ : A view of ACC fronts in streamfunction space. Deep-Sea Res. I, 49, 1141-1164.

Torrence, C., and G. P. Compo, 1998: A practical guide to wavelet analysis. Bull. Amer. Meteor. Soc., 79, 61-78.

Treguier, A.-M., M. H. England, S. R. Rintoul, G. Madec, J. Le Sommer, and J.-M. Molines, 2007: Southern Ocean overturning across streamlines in an eddying simulation of the Antarctic Circumpolar Current. Ocean Sci., 3, 491-507.

_ J. L. Sommer, J.-M. Molines, and B. D. Cuevas, 2010: Response of the Southern Ocean to the southern annular mode: Interannual variability and multidecadal trend. J. Phys. Oceanogr., 40, 1659-1668.

White, W., and R. Peterson, 1996: An Antarctic circumpolar wave in surface pressure, wind, temperature and sea ice extent. Nature, 380, 699-702.

Yuan, X., and D. Martinson, 2001: The Antarctic dipole and its predictability. Geophys. Res. Lett., 28, 3609-3612. 